\title{
Hardly a Tweet Storm
}

W e read with interest the Social Media Vignette, "The Continued Rise in Professional Use of Social Media at Scientific Meetings: An Analysis of Twitter Use During the ASNR 2018 Annual Meeting." "While we agree that there has been an increase in Twitter use during the 5-year period observed, we note that in Table 1, only 96 radiologists tweeted. This compares with an American Society of Neuroradiology membership of more than 4000, representing approximately $2.4 \%$ of the potential pool. Furthermore, as demonstrated in our recent publication, ${ }^{2}$ only 12 of 75 American Neuroradiology Division Chiefs and 4 of 75 academic neuroradiology programs in the United States even had Twitter accounts. We lag behind our colleagues in neurology, neurosurgery, and the neurosciences in embracing social media. As far as Twitter goes, during 1 year (May 1, 2017 to April 30, 2018), only 1 of the neuroradiology programs (University of Southern California) had more than 5 tweets in the year, Mount Sinai had 5 tweets, and the 2 other divisions with Twitter accounts did not tweet at all.

Granted, tweeting at meetings by individuals is different from Neuroradiology Division tweet usage; however, the dissemination of Twitter in neuroradiology circles remains sparse.

http://dx.doi.org/10.3174/ajnr.A6187
We believe a more concerted effort to ramp up the neuroradiology community's use of social media would be helpful in getting our professional "message" out there.

Disclosures: David Yousem—UNRELATED: Expert Testimony: Medicolegal work; Payment for Lectures Including Service on Speakers Bureaus: American College of Radiology Education Center speaker; Royalties: Elsevier for 5 books, Analytical Informatics.

\section{REFERENCES}

1. D'Anna G, Chen MM, McCarty JL, et al. The continued rise in professional use of social media at scientific meetings: an analysis of Twitter use during the ASNR 2018 annual meeting. AJNR Am J Neuroradiol 2019;40:935-37 Medline

2. Charkhchi P, Sahraian S, Beheshtian E, et al. Missed opportunity: neuroradiology training programs and social media. AJR Am J Roentgenol 2019 Mar 5:1-6 [Epub ahead of print] CrossRef Medline

(1) P. Charkhchi

(1) S. Sahraian

(D). Beheshtian

(D) D.M. Yousem

Department of Radiology and Radiological Science

Division of Neuroradiology

The Johns Hopkins Medical Institutions

Baltimore, Maryland 